\title{
Revisiting the Influence of the Quasi-Biennial Oscillation on Tropical Cyclone Activity
}

\author{
SuZANA J. CAMARGO \\ Lamont-Doherty Earth Observatory, The Earth Institute at Columbia University, Palisades, New York
}

ADAM H. SOBEL

Department of Applied Physics and Applied Mathematics, and Department of Earth and Environmental Sciences, Columbia University, New York, New York

(Manuscript received 15 December 2009, in final form 7 June 2010)

\begin{abstract}
The statistical relationship between the quasi-biennial oscillation (QBO) and tropical cyclone (TC) activity is explored, with a focus on the North Atlantic. Although there is a statistically significant relationship between the QBO and TCs in the Atlantic from the 1950s to the 1980s, as found by previous studies, that relationship is no longer present in later years. Several possibilities for this change are explored, including the interaction with ENSO, volcanoes, QBO decadal variability, and interactions with solar forcing. None provides a completely satisfying explanation. In the other basins, the relationship is weaker than in the Atlantic, even in the early record.
\end{abstract}

\section{Introduction}

Tropical cyclone (TC) activity is influenced by the large-scale environment and so is influenced by various natural modes of climate variability. On seasonalto-interannual time scales, the main identifiable factor that influences tropical cyclone activity in most basins is the El Niño-Southern Oscillation (ENSO) phenomenon (Gray 1984a; Camargo et al. 2007a). Besides ENSO, other factors influencing Atlantic TC activity in particular are the Atlantic meridional mode (AMM; Vimont and Kossin 2007; Kossin and Vimont 2007; Kossin et al. 2010), the Atlantic multidecadal oscillation (AMO; Goldenberg et al. 2001; Zhang and Delworth 2006; Zhang 2007; Klotzbach and Gray 2008) and the Madden-Julian oscillation (MJO; Maloney and Hartmann 2000; Mo 2000; Camargo et al. 2009; Klotzbach 2010).

The stratospheric quasi-biennial oscillation $(\mathrm{QBO})$ is a quasi-periodic oscillation of the tropical winds in the stratosphere. The QBO dominates the interannual variability of the equatorial stratosphere, being manifested

Corresponding author address: Suzana J. Camargo, LamontDoherty Earth Observatory, P.O. Box 1000, Palisades, NY 109648000 .

E-mail: suzana@1deo.columbia.edu by alternating periods of easterly $E$ and westerly $W$ zonal winds that descend with time and then repeat with a very well-defined period whose mean is about 28 months. The QBO affects stratospheric dynamics globally and also has documented impacts on the troposphere, such as on winter temperature in North America (Barnston and Livezey 1989). A recent review can be found in Baldwin et al. (2001).

Gray (1984a,b) first pointed out an apparent influence of the QBO on Atlantic TC activity. Gray (1984a) found that when the QBO was in its westerly phase or becoming westerly, TC activity in the Atlantic was greater than when the QBO was in the easterly phase, with more intense Atlantic hurricanes occurring in the westerly QBO years. Correspondingly, the seasonal forecasts of TC activity developed by Gray at Colorado State University (CSU) used the QBO as one of its predictors for many years, although recently the CSU forecasts have ceased using the QBO as a predictor (Klotzbach 2007a,b). Subsequently, the QBO influence on Atlantic hurricane activity has been cited as a factor-in a specific year's level of activity or in the general variability of the Atlantic basin - by other authors (e.g., Shapiro 1989; Hess and Elsner 1994; Landsea et al. 1998; Elsner and Kara 1999; Arpe and Leroy 2009). Additional studies have addressed the possible influence of the QBO on TC 
activity in other regions, such as the western North Pacific (WNP; Chan 1995; Baik and Paek 1998; Lander and Guard 1998; Ho et al. 2009), eastern North Pacific (ENP; Whitney and Hobgood 1997), north Indian Ocean (NI; Balachandran and Guhathakurta 1999), and south Indian Ocean (SI; Jury 1993; Jury et al. 1999).

However, unlike the ENSO influence on Atlantic TCs, the QBO influence does not have a clearly established physical mechanism. Gray et al. (1992a,b) and Arpe and Leroy (2009) ascribed it to the QBO signal in vertical wind shear; however, that signal is restricted to the lower stratosphere, with a very weak extension into the uppermost troposphere. While it is well established that tropospheric shear affects TC formation and intensification, it is much less clear that shear restricted to the uppermost portion of a TC's environment has a significant effect. The QBO effect on static stability has also been cited as a possible influence (Knaff 1993; Arpe and Leroy 2009); however, this explanation appears inconsistent with the sign of the observed QBO-TC correlations in the Atlantic, as pointed out by Shapiro (1989) and discussed further below in section 5d. Shapiro (1989) argued that the QBO influences TCs by affecting the vertical propagation of easterly waves, but this argument too needs to be reconciled with the fact that the QBO shear variations are restricted to the lower stratosphere and uppermost troposphere. Vertical propagation of easterly waves into the stratosphere is weak in any case, and it is not clear that it is a rate-limiting factor in tropical cyclogenesis.

Given our uncertainty about the mechanism, the observed correlation between the QBO and TC activity found by the early studies is particularly intriguing. If the QBO really were to exert an influence on TCs, the need to explain the physical mechanism of this influence would pose an outstanding problem for our understanding of the physics of tropical cyclones and their interaction with the large-scale environment.

Now that 25 years have passed since Gray's pioneering studies, it behooves us to revisit the QBO-TC relationship. In this study, we perform a statistical analysis of the QBO's relationship to TC activity. We look at multiple basins but emphasize the North Atlantic (ATL) because the signal is strongest there.

In section 2, we describe the datasets used in this paper. In section 3, we examine the QBO-TC relationship in the Atlantic, while in section 4 we consider the role of ENSO in this relationship. Section 5 discusses other possible influences on the QBO-Atlantic relationship. The influence of $\mathrm{QBO}$ in other TC prone areas is explored in section 6 and a summary is presented in section 7 .

\section{Data}

Most of the results shown below were obtained using the QBO dataset developed at the University of Berlin (Naujokat 1986; available online at http://www.geo. fu-berlin.de/en/met/ag/strat/produkte/qbo/index.html). This dataset is constructed from radiosonde observations of zonal winds from a few equatorial stations (namely Canton Island, Gan/Maldive Islands, and Singapore). Data are available at multiple pressure levels (70, 50, 40, $30,20,15$, and $10 \mathrm{hPa}$ ). The data at $10 \mathrm{hPa}$ are available from 1957 to the present, while those at the other levels are available from 1953 to the present. We also produced QBO indices by averaging the tropical zonal winds over all longitudes and latitudes $10^{\circ} \mathrm{N}-10^{\circ} \mathrm{S}$ from the National Centers for Environmental Prediction-National Center for Atmospheric Research (NCEP-NCAR) reanalysis (available from 1948 to the present; Kalnay et al. 1996) and the 40-yr European Centre for Medium-Range Weather Forecasts (ECMWF) Re-Analysis (ERA-40; available from September 1957 to August 2002; Uppala et al. 2005), and a few results using these data are also shown here. Both reanalyses have been extensively studied for their reproduction of the QBO (e.g., Huesmann and Hitchman 2001, 2003; Ribera et al. 2003; Baldwin and Gray 2005; Pascoe et al. 2005; Punge and Giorgetta 2007). The reanalysis data are available at pressure levels, including 70, 50, 30, 20, and $10 \mathrm{hPa}$. Although the NCEP-NCAR reanalysis is available from 1948 to the present, there is a trend in the equatorial stratospheric zonal winds in the first few years that is different from anything occurring in the rest of the record. As this appears somewhat suspect, we use the same start date as that of the Berlin dataset (1953) for our calculations with the NCEP-NCAR QBO index. We also used the National Oceanic and Atmospheric Administration/Climate Prediction Center (NOAA/CPC) QBO index (available from 1979 to the present) in our analysis (available online at http://gcmd.nasa.gov/records/GCMD_NOAA_NWS_ CPC_QBO.html).

To compare with the annual statistics of TC activity, we produce QBO indices with annual resolution by averaging the various stratospheric zonal wind products described above over the period June-November (JJASON), encompassing the Atlantic TC season. Most of our results presented below use the zonal wind at $30 \mathrm{hPa}$ to define the QBO phase, as was done by Gray (1984a,b). Using other levels can change the results; since the QBO descends with time, its phase (and thus the sign of the zonal wind) generally changes with height, and the correlation of any given time series with a QBO index at one level can vanish or change sign if another level is used. We repeated our analyses with the QBO index defined at 

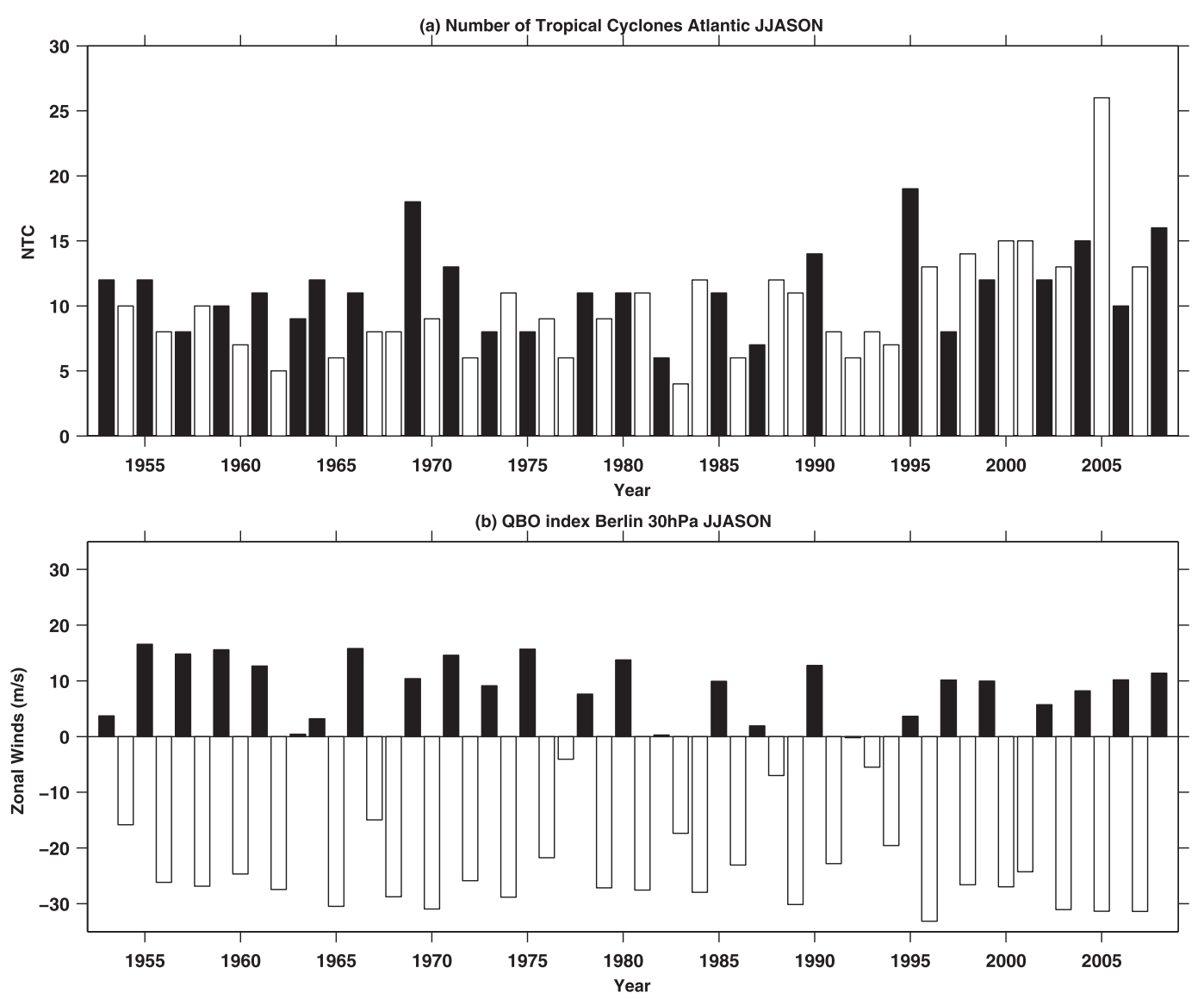

FIG. 1. (a) Number of tropical cyclones in the JJASON season in the Atlantic basin. (b) Berlin QBO index at $30 \mathrm{hPa}$ for the same season (JJASON).

various levels and did not find a statistically significant stronger relationship between the QBO and TC activity using a pressure level other than $30 \mathrm{hPa}$.

To be sure that our results are independent of the tropical cyclone dataset used, we performed our analysis with the best-track datasets from the National Hurricane Center (Atlantic and eastern North Pacific) and the Joint Typhoon Warning Center (western North Pacific, north Indian Ocean, and Southern Hemisphere), as well as the newly developed International Best Track Archive for Climate Stewardship (IBTrACS) global dataset for TC activity (Knapp et al. 2009, 2010; Kruk et al. 2010). Our analysis only considers data until 2008. For the Atlantic, only results computed with the National Hurricane Center best-track dataset are shown, whereas for the other basins, we only show results with the IBTrACS data.

The ENSO index used was the Niño-3.4 (Barnston et al. 1997) sea surface temperature index also available from CPC (available online at http://www.cpc.ncep.noaa. gov/data/indices/), and solar activity is represented by the $10.7-\mathrm{cm}$ solar flux from the National Geophysical Data
Center (available online at http://www.ngdc.noaa.gov/stp/ solar/flux.html).

\section{Atlantic $\mathbf{T C}$ activity and $\mathbf{Q B O}$}

Figure 1 shows in the top panel the number of tropical cyclones (NTC) in the Atlantic basin per year that reach tropical storm intensity $(35 \mathrm{kt})$ or higher, whereas the bottom panel shows the Berlin QBO index at $30 \mathrm{hPa}$. Years in which the QBO phase is westerly at $30 \mathrm{hPa}$ are represented by black bars in both panels, whereas easterly years are represented by white bars. It is apparent that in the early part of the record there is a tendency for the black bars to exceed the white but that ceases to be the case in the later part of the record.

The correlations between NTC and other TC activity indices [number of hurricanes (NHUR), number of major hurricanes $(\mathrm{NMH})$, number of hurricane days (NHD), and accumulated cyclone energy (ACE)] in the Atlantic with the Berlin QBO indices at various pressure levels are given in Table 1 . The correlation is not significant for any TC index or QBO level considered. 
TABLE 1. Correlation coefficients $(\times 100)$ of various Atlantic TC indices (NTC, NHUR, NMH, and ACE) and the Berlin QBO index in various pressure levels in the period 1953-2008 (exception, $10 \mathrm{hPa}:$ 1957-2008) for the JJASON season. None of the correlation values is statistically significant.

\begin{tabular}{crrrrr}
\hline \hline $\begin{array}{c}\text { Level } \\
(\mathrm{hPa})\end{array}$ & NTC & NHUR & NMH & NHD & ACE \\
\hline 70 & 15 & 12 & 19 & 12 & 16 \\
50 & 14 & 14 & 24 & 21 & 20 \\
40 & 08 & 09 & 19 & 18 & 15 \\
30 & 08 & 11 & 18 & 21 & 17 \\
20 & 04 & 12 & 05 & 17 & 10 \\
15 & 00 & 08 & -04 & 08 & 03 \\
10 & -06 & -02 & -12 & -08 & -08 \\
\hline
\end{tabular}

Because the distribution of equatorial stratospheric zonal winds is bimodal, we construct sets of years that are either easterly or westerly and examine the distributions of Atlantic TC activity indices that occur in these two phases. These distributions are shown in Fig. 2. There is a clear hint of higher TC activity when the QBO is in the westerly phase. We applied statistical tests to determine if the distributions have different characteristics: a double-sided $t$ test for the means, Mann-Whitney $U$ test for the medians, and a chi-square test for the variances. When El Niño (EN) years are removed (as Gray did) most of our first two tests show significant differences between the means, medians, or both, though the Kolmogorov-Smirnov test does not. When El Niño and La Niña (LN) are both removed (eliminating an additional $13 \mathrm{yr}$; 6 in the westerly QBO phase, 7 in the easterly phase), most of the significance disappears. The distributions were considered distinct as shown in Table 2. We did not do this analysis considering only fractions of the record, as the sample size is too small.

To confirm that the lack of relationship between Atlantic TC activity and QBO index was not dependent on
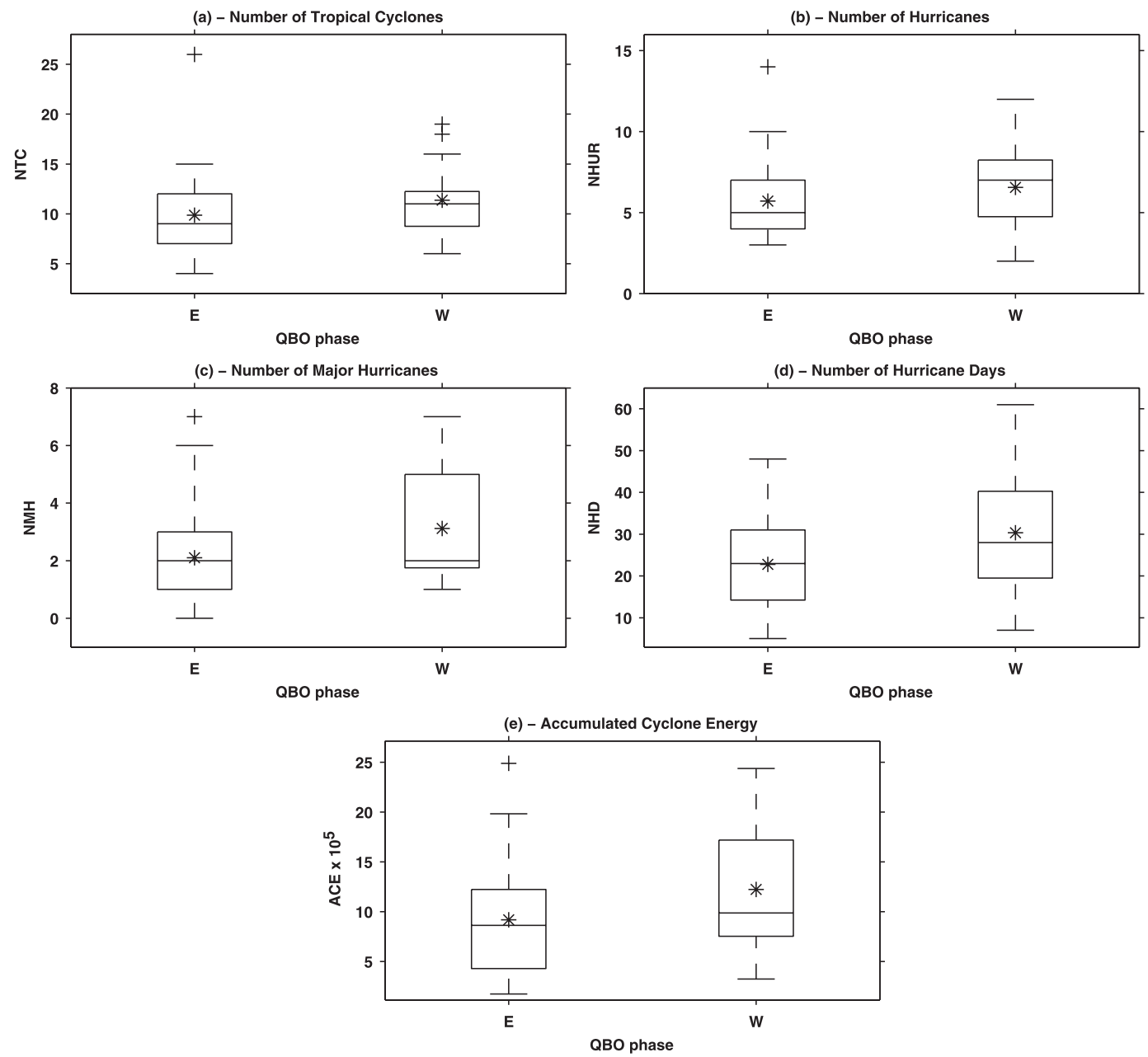

FIG. 2. Distribution of (a) number of tropical cyclones, (b) number of hurricanes, (c) number of major hurricanes, (d) number of hurricane days, and (e) accumulated cyclone energy, for $E$ and $W$ phases of the QBO. 
TABLE 2. Statistical significance of tests comparing the distributions of various Atlantic TC indices in $E$ and $W$ QBO phases. The tests are applied for all years, excluding El Niño years [i.e. non-El Niño years (NEN)], and also for different ENSO phases: El Niño (EN), La Niña (LN), and neutral (NT). Note that for $\mathrm{EN}$ and $\mathrm{LN}$ the distributions have very few years. The number of years in each $E$ and $W$ distribution is given in columns 3 and 4. A null result indicates that the null hypothesis (e.g., that the means are equal) cannot be rejected at the 5\% level. The KolmogorovSmirnov test is denominated KS. Only cases with at least one statistical significant result are shown.

\begin{tabular}{llrrrrrr}
\hline \hline Variable & Yr & \multicolumn{1}{c}{ No. of $E$} & No. of $W$ & Mean & Median & Variance & KS \\
\hline NMH & All & 31 & 25 & 1 & 0 & 0 & 0 \\
NHD & All & 31 & 25 & 1 & 1 & 0 & 0 \\
NHUR & NEN & 27 & 16 & 0 & 1 & 0 & 0 \\
NMH & NEN & 27 & 16 & 1 & 1 & 0 & 0 \\
NHD & NEN & 27 & 16 & 1 & 1 & 0 & 0 \\
ACE & NEN & 27 & 16 & 1 & 0 & 0 & 0 \\
NTC & NT & 21 & 9 & 0 & 0 & 1 & 1 \\
NHUR & NT & 21 & 9 & 0 & 1 & 0 & 0 \\
NTC & EN & 4 & 9 & 0 & 1 & 1 & 0 \\
NHUR & EN & 4 & 9 & 0 & 0 & 1 & 0 \\
NMH & LN & 4 & 9 & 0 & 0 & 1 & 0 \\
\hline
\end{tabular}

the QBO index used, we repeated these calculations with various $\mathrm{QBO}$ indices, including those calculated from reanalysis data. As shown in Table 3 for 70, 50, and $30 \mathrm{hPa}$ and four different QBO indices and various TC activity index, the correlations are not significant for any of the QBO indices or TC variables used.

These results seem to indicate the absence of a robust relationship between the QBO and Atlantic TC activity, in contrast to the conclusions of the earlier studies by Gray (1984a) and Gray et al. (1992b). As suggested by Fig. 1, this is due to a change in the relationship around the time of those studies. Table 4 shows the correlations of Atlantic TC activity indices and the Berlin QBO at $30 \mathrm{hPa}$ for the full period analyzed (1953-2008) and then the correlations obtained by dividing that period into either two or three shorter periods. The correlations in the first part of the record, either defined as 1953-82 or 1953-70, are statistically significant for all the TC indices considered, in most cases at the $99 \%$ significance level. In contrast, in the later periods, these correlations are not significant. It should be noted that at $70 \mathrm{hPa}$, the level used in the analysis in Arpe and Leroy (2009), the correlation does not change for different time periods, as occurs at $30 \mathrm{hPa}$, but it is not statistically significant at any of the time periods. Significance here was tested using a bootstrap: we made 10000 random permutations of each of the time series, calculated the correlations, and found the top 99 (95) and bottom 1 (5) percentile values.

In Fig. 3, we show a time series of rolling 30-yr correlations computed for each 30 -yr period ending on the year shown on the $x$ axis. As expected from the results
TABLE 3. Correlation coefficients $(\times 100)$ of various Atlantic TC indices (NTC, NHUR, NMH, and ACE) and the Berlin, CPC, NCEP-NCAR reanalysis, and ERA-40 reanalysis, at 70, 50, and $30 \mathrm{hPa}$. The reanalysis indices were obtained by averaging the zonal winds from $10^{\circ} \mathrm{S}$ to $10^{\circ} \mathrm{N}$.

\begin{tabular}{lrcrrrrr}
\hline \hline Dataset & Period & \multicolumn{7}{c}{ Level (hPa) } & NTC & NHUR & NMH & NHD & ACE \\
\hline Berlin & $1953-2008$ & 70 & 15 & 12 & 19 & 12 & 16 \\
Berlin & $1953-2008$ & 50 & 14 & 14 & 24 & 21 & 20 \\
Berlin & $1953-2008$ & 30 & 08 & 11 & 18 & 21 & 17 \\
CPC & $1979-2008$ & 50 & -01 & 00 & 08 & 08 & 03 \\
CPC & $1979-2008$ & 30 & -13 & -10 & -03 & -01 & -04 \\
NCEP & $1953-2008$ & 70 & 26 & 15 & 16 & 09 & 16 \\
NCEP & $1953-2008$ & 50 & 17 & 14 & 22 & 18 & 20 \\
NCEP & $1953-2008$ & 30 & 06 & 11 & 17 & 21 & 16 \\
ERA-40 & $1958-2001$ & 70 & 26 & 21 & 23 & 14 & 20 \\
ERA-40 & $1958-2001$ & 50 & 25 & 24 & 26 & 24 & 24 \\
ERA-40 & $1958-2001$ & 30 & 20 & 23 & 17 & 25 & 21 \\
\hline
\end{tabular}

above, these correlations are significant in the early part of the record but decrease for later years until becoming very near zero and then negative. Very similar results are obtained if rank correlations are used instead of linear correlations. In summary, somewhere between the 1980s and the 1990s the QBO relationship with Atlantic TCs seems to have changed. It is hard to pinpoint the "exact" year that this occurred because with a biennial frequency it takes a decade or two to have a meaningful sample.

\section{ENSO influence}

Because ENSO is known to have a strong influence on Atlantic TC activity, and ENSO and the QBO have similar time scales, we must ask whether any apparent correlation between the QBO and TC activity might be an artifact of the ENSO influence on the latter, combined with some (presumably coincidental) correlation between the QBO and ENSO. Previous studies looking for a QBO-ENSO relationship have come to a range of

TABLE 4. Correlations $(\times 100)$ of Berlin QBO index and various Atlantic TC indices for different time periods. Statistically significant correlations at the $95 \%(99 \%)$ level are indicated by an asterisk (double asterisk). The statistical significance was obtained by doing 10000 random permutations of both time series and calculating their correlations. Similar results are obtained with the rank correlation.

\begin{tabular}{lccccc}
\hline \multicolumn{1}{c}{ Period } & NTC & NHUR & NMH & NHD & ACE \\
\hline $1953-2008$ & 08 & 11 & 18 & 21 & 17 \\
$1953-82$ & $44^{*}$ & $42^{*}$ & $37^{*}$ & $47^{* *}$ & $46^{*}$ \\
$1983-2008$ & -12 & -13 & -01 & -06 & -06 \\
$1953-70$ & $62^{* *}$ & $57^{*}$ & $56^{*}$ & $67^{* *}$ & $69^{* *}$ \\
$1971-88$ & 14 & 28 & 21 & 24 & 20 \\
$1989-2008$ & -18 & -22 & -10 & -10 & -11 \\
\hline
\end{tabular}



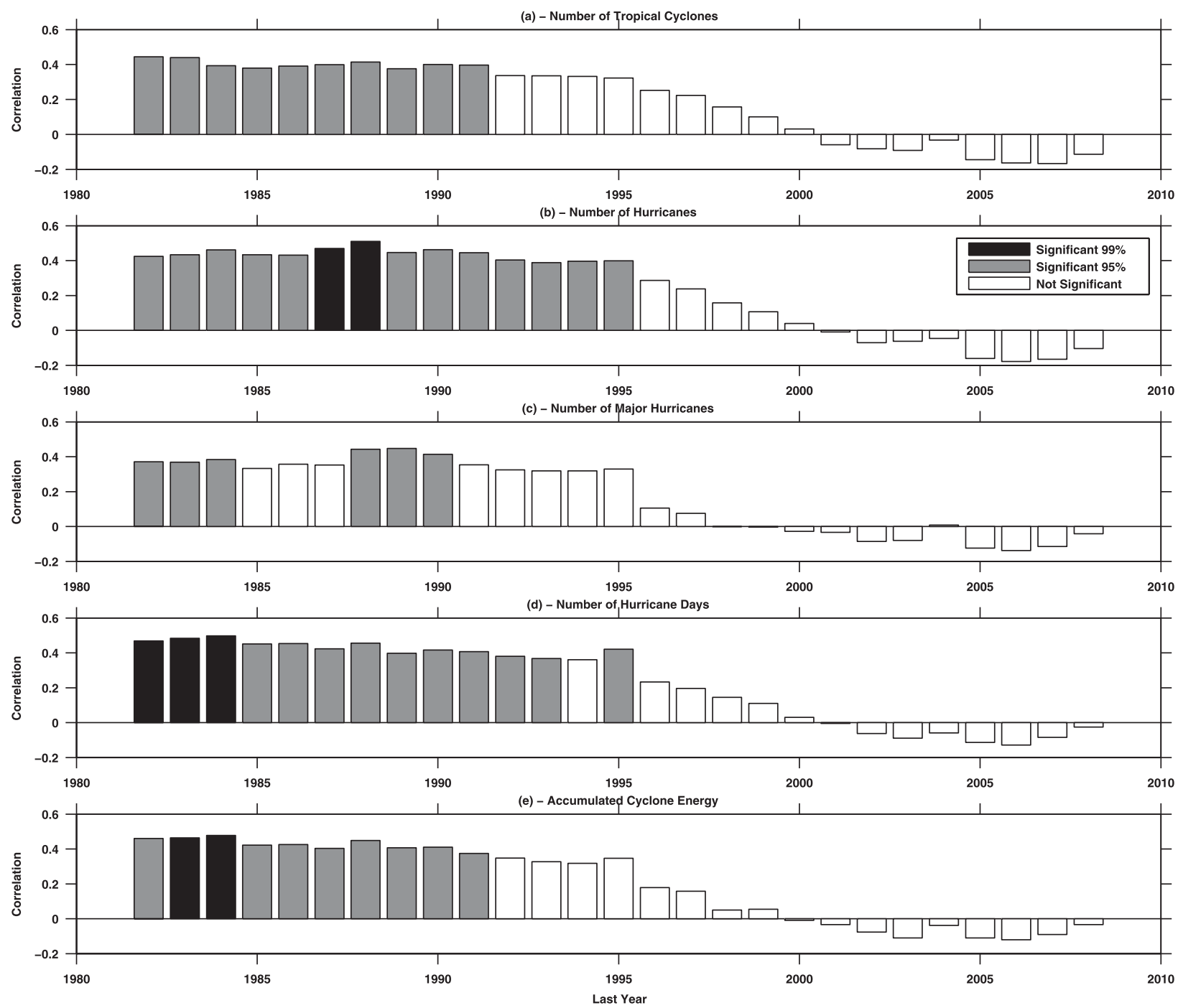

FIG. 3. 30-yr correlations of Berlin $30 \mathrm{hPa}$ QBO with (a) number of tropical cyclones, (b) number of hurricanes, (c) number of major hurricanes, (d) number of hurricane days, and (e) accumulated cyclone energy. The first correlation (first bar) is calculated for the period 1953-82, the subsequent one is calculated for the next 30-yr period (1954-83), until in the last bar the last 30 yr are considered (1979-2008). The $x$ axis shows the last year that was included in the calculation. The statistical significance is calculated by bootstrap.

different conclusions (Wallace and Chang 1982; Quiroz 1983; van Loon and Labitzke 1987; Barnston et al. 1991).

Gray (1984a) handled this issue by restricting his analysis to years in which there was no El Niño event occurring. Since La Niña years were not removed, we might argue that the effects of the ENSO phenomenon are not entirely eliminated. Table 2 suggests that the effect of La Niña may be consequential, although Table 5, discussed below, suggests otherwise.

Scatterplots of all Atlantic TC variables and QBO are shown in Fig. 4 for the period 1953-82. The ENSO state and the period of the season are defined by the symbol types. The definition of ENSO state was based on the value of Niño-3.4 (Barnston et al. 1997) in August-October
(ASO) for the period 1950-2008, with the top (bottom) quartile of the distribution defined as El Niño (La Niña) years and the middle two quartiles as neutral (NT) years. This is the same definition used in, for example, Camargo and Sobel (2005) and Camargo et al. (2007b). There are, for instance, more hurricane days when the QBO is in a westerly phase than in an easterly one. This is particularly clear, as shown in the regression line, especially if El Niño years are not considered (circles), which is basically the result shown by Gray (1984a). However, when all years are considered (not shown) the regression lines are almost flat, expressing the lack of relationship between the quantities displayed (TC indices and QBO). 
TABLE 5. Correlations $(\times 100)$ of Berlin QBO index and various Atlantic TC indices for different time periods in non-El Niño (NT and LN, or NEN) and in NT-only years. Statistically significant correlations at the $95 \%$ (99\%) level are indicated by an asterisk (double asterisk). The statistical significance was obtained by doing 10000 random permutations of both time series and calculating their correlations. Similar results are obtained with the rank correlation.

\begin{tabular}{llccrcc}
\hline \hline \multicolumn{1}{c}{ Yr } & \multicolumn{1}{c}{ Period } & NTC & NHUR & NMH & NHD & ACE \\
\hline NEN & $1953-2008$ & 03 & 13 & 15 & 24 & 15 \\
NEN & $1953-82$ & $46^{*}$ & $52^{* *}$ & 33 & $53^{* *}$ & $46^{*}$ \\
NEN & $1983-2008$ & -12 & -04 & -03 & 02 & -07 \\
NT only & $1953-2008$ & -05 & 08 & 02 & 11 & 02 \\
NT only & $1953-82$ & $46^{*}$ & $57^{*}$ & 32 & $55^{*}$ & $46^{*}$ \\
NT only & $1983-2008$ & -21 & -16 & -25 & -26 & -33 \\
\hline
\end{tabular}

Table 5 shows the correlations for the different subsets of the record for non-El Niño years (NEN; i.e., La Niña and neutral years) and for neutral years only. Similar to the results obtained when all years were considered, in both cases, the correlations for most Atlantic TC variables (with the exception of the number of major hurricanes) are statistically significant for the early period of the record (1953-82) but not for the later period or for the record as a whole.

While removing strong ENSO events from the record does not destroy the correlation in the early record, it could still be that the change in the QBO-TC relationship is a result of ENSO influence, if the relationship between the QBO and ENSO were to change over time such that in the later record ENSO were to tend (coincidentally) to counteract the QBO influence on TCs. Figure 5 shows rolling 30-yr correlations between QBO and Niño-3.4, using the same format as in Fig. 3. Indeed, we see that the sign of the QBO-ENSO correlation changes in the middle of the record. In the early record, it is negative, such that El Niño (La Niña) events are more common when the QBO is easterly (westerly) at $30 \mathrm{hPa}$, whereas the opposite is true in the later record. The correlations are not large, but they are significant at the $95 \%$ level for the first few and last few 30 -yr periods. This is at least qualitatively consistent with a role for ENSO influence in the change of the QBO-TC relationship.

On the other hand, Fig. 6 shows 30-yr partial correlations of QBO and TC indices, linearly removing the influence of ENSO. The early record retains a significant correlation between the QBO and TCs (again consistent with Gray's original analysis) while the later record still has none. To the extent that linear partial correlation is an appropriate statistic, this is evidence against ENSO influence as the explanation for the change in the QBOTC relationship.

We are left with a suggestive but inconclusive picture. The ENSO-QBO correlation does change sign at a similar point in the record to that at which the QBOTC correlation changes sign, in such a way as to suggest that the apparent QBO-TC correlation might be at least partially a result of ENSO influence on TCs combined with a QBO-ENSO correlation. However, removing ENSO either by partial correlation or by simply omitting El Niño and La Niña years from the record does not change the result that the QBO-TC correlation is significant in the early record and insignificant in the later record.

\section{Other possible influences on the QBO-TC relationship}

In this section, we briefly consider several other possible reasons (besides ENSO) for the change in the relationship between QBO and Atlantic TC activity.

\section{a. Decadal variability}

The appearance or disappearance of a significant interannual correlation on a decadal or multidecadal time scale does not necessarily imply that the correlation is spurious. A potentially relevant example here is the correlation between the QBO and the strength of the Northern Hemispheric polar vortex. This correlation has a well-accepted physical mechanism, involving the influence of the tropical stratospheric winds on planetary wave refraction, which is the so-called Holton-Tan effect (Holton and Tan 1980, 1982). Lu et al. (2008) showed that the strength of the Holton-Tan effect has varied on decadal scales, becoming statistically insignificant during 1977-97 after being significant before that but strengthening again in the most recent decade. Anstey and Shepherd (2008) showed a relationship between the timing of the QBO phase transition with respect to the annual cycle and the strength of the Holton-Tan effect and proposed this as an explanation for the decadal variations in the latter. There is also a well-known climate shift that occurred in 1976-77, that is, simultaneously with the change in the Holton-Tan effect. This climate shift has been related to the Pacific decadal oscillation, which is linked to changes in the frequency and intensity of ENSO events (Trenberth and Hurrell 1994; Zhang et al. 1997; Watanabe and Nitta 1999; Karspeck and Cane 2002).

As the transition from a strong Holton-Tan effect to a weak one occurs around 1977, a time within a few years of that at which the QBO-TC relationship weakens, we might be tempted to look for an explanation that connects the two. For example, variations in strength of the stratospheric polar vortex are now widely recognized to influence tropospheric climate and weather in the Northern Hemisphere during winter (e.g., Baldwin 

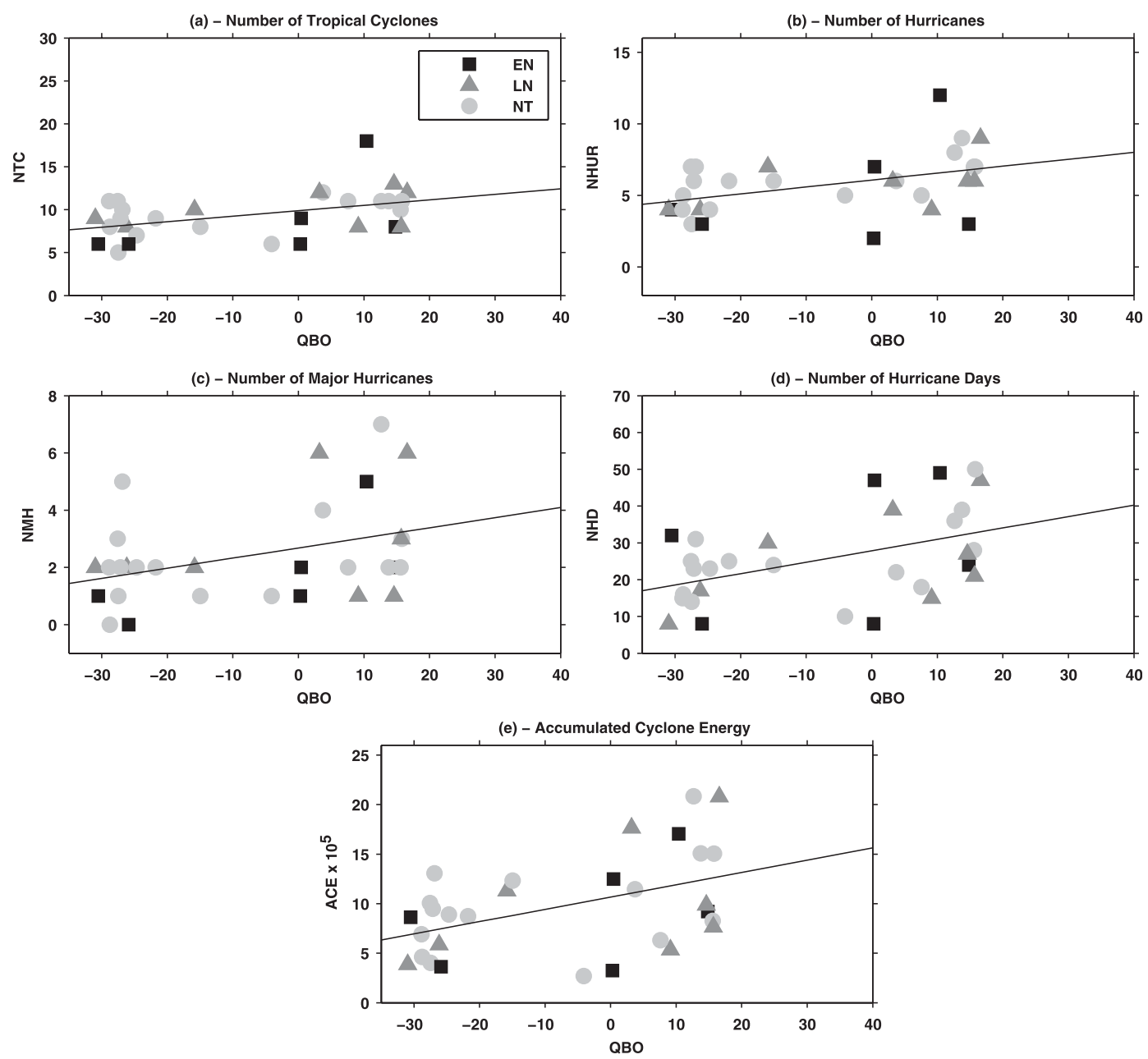

FIG. 4. Scatterplots of Berlin 30-hPa QBO with (a) number of tropical cyclones, (b) number of hurricanes, (c) number of major hurricanes, (d) number of hurricane days, and (e) accumulated cyclone energy. The lines shown in each panel are the regression lines. The symbols (squares, triangles, and circles) are for El Niño (EN), LN, and NT years, respectively.

and Dunkerton 2001; Polvani and Kushner 2002), and variations in the final warming date influence the spring climate (Black et al. 2006). It is conceivable that some of this influence might perhaps be transmitted to the tropical oceans in the following summer season and thus influence Atlantic TC activity; the latter is known to be influenced, directly or indirectly, by the annular modes or the North Atlantic Oscillation (Knaff 1998; Elsner and Kara 1999; Klotzbach and Gray 2004; Kossin and Vimont 2007; Frank and Young 2007; Kossin et al. 2010).

To explore this, following $\mathrm{Lu}$ et al. (2008) we break our time series into three separate pieces: 1957-76, 1977-97, and 1998-2008 and compute correlations between the QBO and TC activity indices for those periods separately. The results are shown in Table 6. In contrast to the QBO-polar vortex correlations examined by $\mathrm{Lu}$ et al. (2008), the correlations of the QBO and the Atlantic TC indices do not increase to statistically significant values after 1997.

These results do not suggest any connection (beyond coincidence) between the changes in the QBO-TC relationship and those in the QBO-polar vortex relationship. When we also consider that the QBO-polar vortex correlations computed by $\mathrm{Lu}$ et al. (2008) are statistically significant when the full time series is considered (1958-2007), whereas the same is not true of the QBOTC relationship, and that the physical explanation for the Holton-Tan effect has been more thoroughly elucidated (including an explicit and well-understood idealized dynamical model) than any of those for the QBO-TC relationship. Therefore, it appears that the decadal changes in the Holton-Tan effect can be explained (without rejecting the hypothesis that there is a genuine 


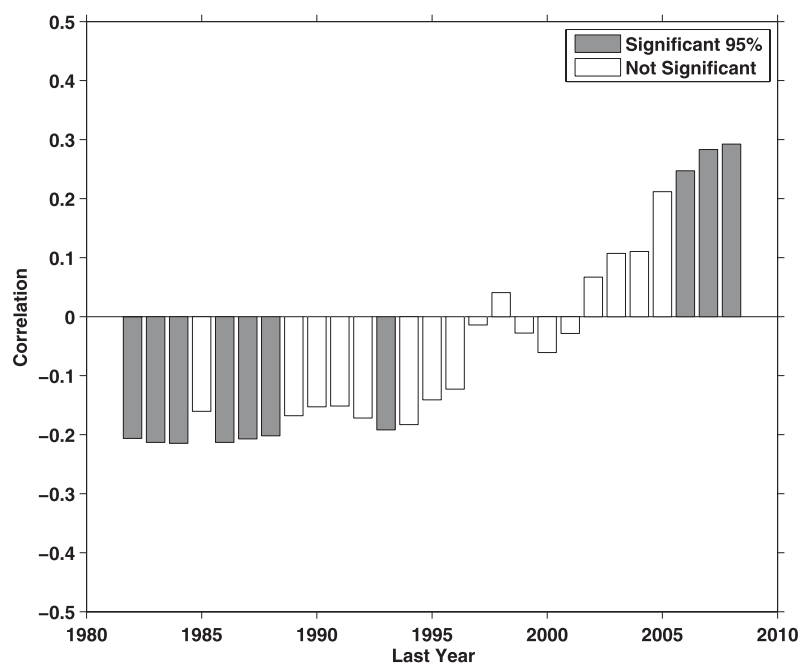

FIG. 5. 30-yr correlations of Berlin 30-hPa QBO JJASON and Niño-3.4 ASO. The first correlation (first bar) is calculated for the period 1953-82, the subsequent one is calculated for the next 30-yr period (1954-83), until in the last bar the last $30 \mathrm{yr}$ are considered (1979-2008). The $x$ axis shows the last year that was included in the calculation. The statistical significance is calculated using bootstrap.

QBO influence) more easily than those in the QBO-TC relationship.

\section{b. Solar signal and $Q B O$}

We examine the possibility that the change in the relationship between QBO and TC activity may be attributed to the solar cycle. We construct the mixed solarQBO index of Haigh and Roscoe (2006) and Roscoe and Haigh (2007) as the product of the solar and the QBO indices. The mean of each index is subtracted before the product is calculated. The resulting time series are shown in Fig. 7: the normalized solar index, the normalized QBO index, and the combined normalized solar-QBO index.

Table 7 shows the correlations of the Atlantic TC activity and the normalized solar index in JJASON. None of the correlations obtained are statistically significant. Figure 8 shows the 30 -yr correlations of the Atlantic TC activity variables and the combined solarQBO index in JJASON. Similar to the results with the QBO index only, these correlations are statistically significant in the first part of the record and then become smaller and insignificant, changing sign in the last 30-yr intervals. Given the similarity with the results obtained from the QBO index only, and the lack of correlations of TC activity with the solar index, we can conclude that this pattern is due to the relationship of QBO and Atlantic TC activity or lack thereof.

As an aside, we note that the lack of correlation between the solar index alone and TC activity shown in Table 7 might suggest a conclusion different than that of
Elsner and Jagger (2008) and Elsner et al. (2010). Elsner and Jagger (2008) found a relationship between intense hurricanes and solar activity using quantile regression, and Elsner et al. (2010) attributed this relationship to changes in the outflow temperature induced by ultraviolet radiation. Because our methods are different, the results are not necessarily inconsistent. As our interest is in the QBO, we do not attempt to reach any strong conclusions about the influence of solar activity on Atlantic TC activity, but we simply conclude that solar activity does not seem to explain the change in the QBO-TC relationship during the record.

\section{c. Volcanoes}

Strong volcanic eruptions in the tropics have a widely recognized and relatively well-understood impact on the stratospheric circulation as well as on tropospheric climate. We might expect that volcanic eruptions occurring randomly with different phase relationships to the QBO can either increase or decrease the QBO-TC correlation.

To test whether volcanoes might explain the decadal change in that correlation we exclude the years when we expect a strong influence from the three major tropical eruptions occurring during our period of interest: Agung (1963), El Chichon (1982), and Pinatubo (1991). Following Randel et al. (2009) to avoid the influence of these events in the stratosphere, we omit the year of the eruption itself and the two years following each eruption from our time series: 1963-65, 1982-84, and 1991-93. It should be mentioned that the years of these volcanic eruptions (1963, 1982, and 1991) also were El Niño years.

Table 8 shows the correlations of the QBO and TC activity in the Atlantic after these years are removed. The results shown in the preceding sections are not substantially changed - the correlations for the full period continue to be statistically insignificant, and the correlations prior to 1982 are still significant. We obtain similar results when excluding only the years of the volcanic eruptions, the years of the volcanic eruptions, and only one year after the eruptions (not shown).

\section{d. Outflow temperature}

One physical hypothesis for the QBO influence on tropical cyclones involves the lower-stratospheric temperature. The lower-stratospheric temperature does vary with the QBO, as required to keep the mass and wind fields in balance (Plumb and Bell 1982); and the potential intensity (PI), the theoretical upper limit for TC intensity based on thermodynamic arguments (Emanuel 1988, 1995), does in general depend on the lower-stratospheric temperature.

We examined the relationship between the QBO and the TC outflow temperature in the tropics, computing 

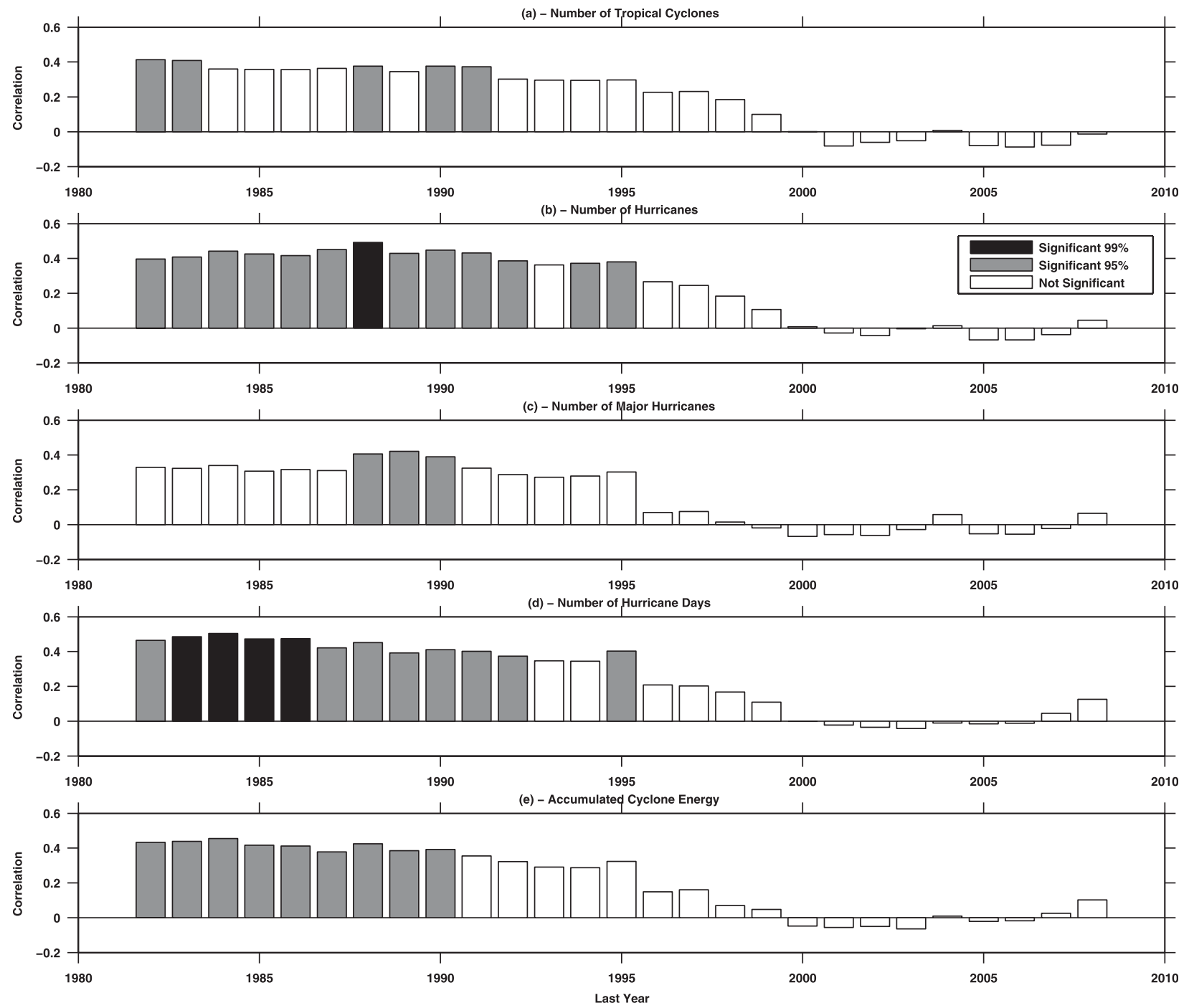

FIG. 6. 30-yr partial correlations of Berlin $30 \mathrm{hPa}$ QBO with (a) number of tropical cyclones, (b) number of hurricanes, (c) number of major hurricanes, (d) number of hurricane days, and (e) accumulated cyclone energy, taking into account the relationship with Niño-3.4 ASO. The first correlation (first bar) is calculated for the period 1953-82, the subsequent one is calculated for the next 30-yr period (195483), until in the last bar the last $30 \mathrm{yr}$ are considered (1979-2008). The $x$ axis shows the last year that was included in the calculation. The statistical significance is calculated by bootstrap.

the latter using the PI algorithm of Emanuel (1995) as modified by Bister and Emanuel (1998) and using the NCEP-NCAR reanalysis dataset. ${ }^{1}$ The PI algorithm yields outflow temperature as part of the calculation. The outflow temperature in the tropics and the QBO has a positive and significant correlation until the late 1970s but not after that. The positive correlation in the early record does not explain the QBO-TC correlation in that part of the record, however, because the sign is incorrect.

\footnotetext{
${ }^{1}$ Outflow temperature data were kindly provided by Professor Kerry Emanuel.
}

The PI argument would require outflow temperature to be anomalously low during periods of anomalously high TC activity, which in the early part of the record tend to be associated with positive QBO index. An explanation of the QBO-TC correlation in terms of outflow temperature would require a negative QBO-outflow temperature correlation, the opposite of what is observed. This was pointed out by Shapiro (1989-his explanation was phrased in terms of the lower-stratospheric temperature rather than outflow temperature per se, but the essence is the same). Indeed, Collimore et al. (2003) find a zonal mean enhancement in the deepest convection during easterly QBO years; this is consistent with 
TABLE 6. Correlations $(\times 100)$ of Berlin QBO index and various Atlantic TC indices for different time periods. Statistically significant correlations at the $95 \%(99 \%)$ level are indicated by an asterisk (double asterisk).

\begin{tabular}{lccccc}
\hline \hline \multicolumn{1}{c}{ Period } & NTC & NHUR & NMH & NHD & ACE \\
\hline $1958-76$ & $54 * *$ & $60 * *$ & $41 *$ & $55 * *$ & $53 * *$ \\
$1977-97$ & 11 & 8 & -12 & 2 & 0 \\
$1998-2008$ & -40 & -36 & 11 & -14 & -10 \\
$1958-2008$ & 7 & 11 & 13 & 18 & 13 \\
\hline
\end{tabular}

what one would expect physically, but it is inconsistent with what is needed to explain the QBO-TC correlation. TC activity in the early record is enhanced during the westerly QBO phase. In the tropical mean, the lower stratosphere is anomalously warm, not cold, during that phase, which is inconsistent with the hypothesis that the QBO-TC relationship is determined by static stability considerations.

On the other hand, tropopause temperature anomalies in the westerly QBO phase have a characteristic spatial structure. The tropopause warming is found in the zonal mean equatorward of roughly $15^{\circ} \mathrm{N} / 15^{\circ} \mathrm{S}$, whereas tropopause and lower-stratospheric cooling are found poleward of that (Randel et al. 2000; Baldwin et al. 2001). In the North Atlantic in particular, the cooling begins at a lower latitude compared to other longitudes, as can be seen from QBO composites (westerly minus easterly phases) of 100-hPa temperature from the ERA-40 reanalysis (not shown). Thus, the objection above (as per Shapiro 1989) does not appear to apply to the North Atlantic. Arpe and Leroy (2009) argue that the subtropical upper-tropospheric and lower-stratospheric cooling in the Atlantic when associated could be responsible for the TC enhancement associated with the QBO westerly phase there.

While this is plausible, it does not seem to explain the observed time history of the QBO-TC relationship. We computed the correlation coefficients between the QBO index at different levels and the 100 -hPa temperature in the tropical North Atlantic for ASO and JJASON from ERA-40 for the presatellite and satellite eras (1958-78 and 1979-2001). The correlations are not statistically significant (0.1-0.2) when the QBO index at $30 \mathrm{hPa}$ is
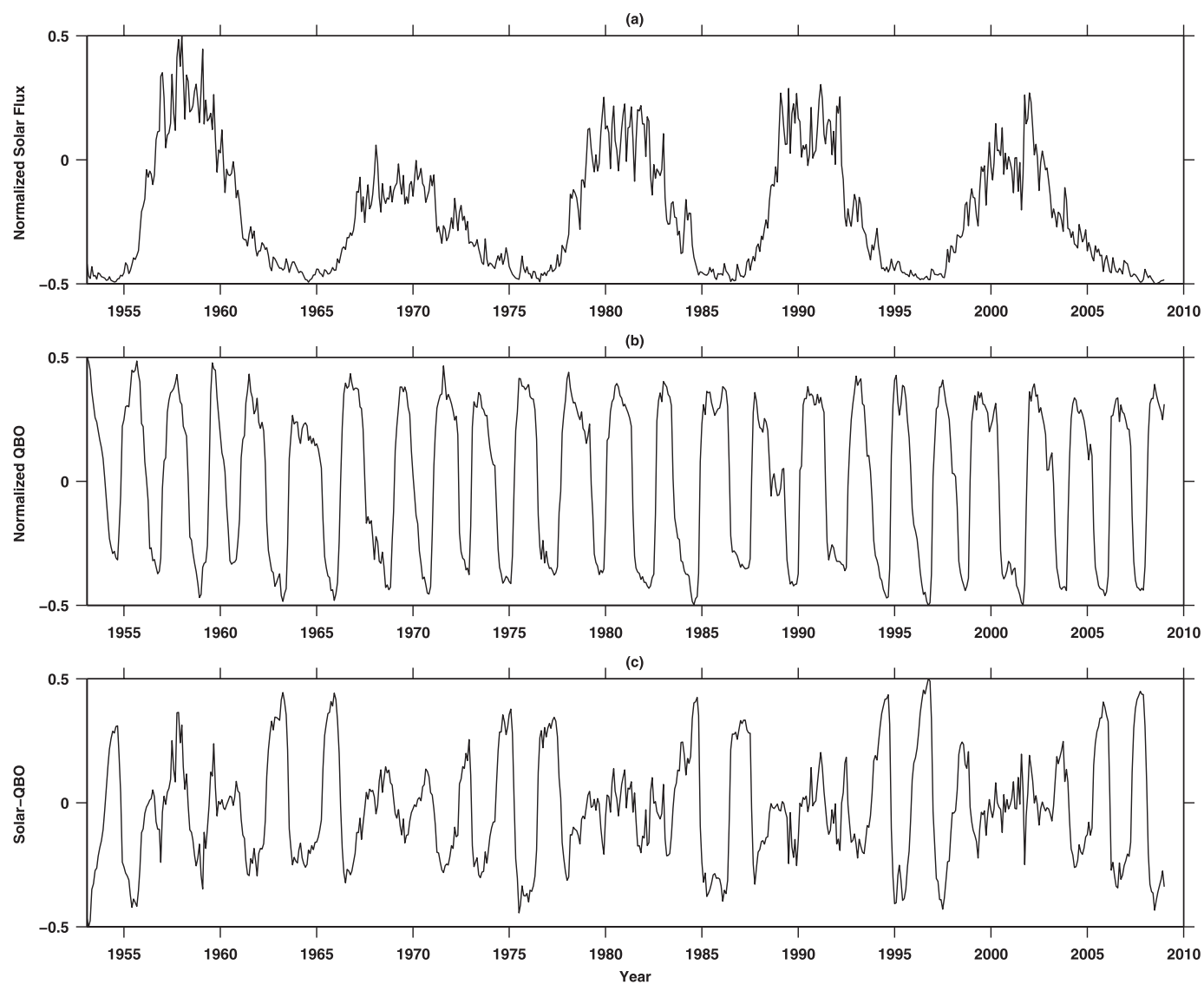

FIG. 7. Time series of (a) the normalized solar flux index, (b) the normalized QBO index, and (c) the combined normalized solar-QBO index in the period 1953-2008. 
TABLE 7. Correlations $(\times 100)$ of solar index and various Atlantic TC indices for different time periods. None of the correlations has statistical significance at the $95 \%$ (99\%) level.

\begin{tabular}{lrrrrr}
\hline \hline \multicolumn{1}{c}{ Period } & NTC & NHUR & NMH & NHD & ACE \\
\hline $1947-2008$ & -2 & -1 & -6 & -1 & -5 \\
$1947-82$ & 4 & -3 & -6 & -5 & -6 \\
$1983-2008$ & 0 & 4 & -5 & 3 & -1 \\
\hline
\end{tabular}

used (as we have, as well as Gray's original work). The correlations are larger when $70 \mathrm{hPa}$ is used, but they are of opposite sign (presumably because the QBO indices at 30 and $70 \mathrm{hPa}$ are generally out of phase, so the westerly events at $30 \mathrm{hPa}$ are easterly events at $70 \mathrm{hPa}$ ) and still remain insignificant for the earlier period. Because the QBO-TC relationship was observed to be significant in the early record and not in the later record, and because the QBO-TC correlations are such that westerly events at $30 \mathrm{hPa}$ are associated with enhanced TC activity in the early record, these correlations cannot explain the observed QBO-TC relationship in either the early record or the record as a whole.

We have performed similar calculations with the outflow temperature now considering the North Atlantic only. The correlations between the QBO index at $30 \mathrm{hPa}$ and North Atlantic outflow temperature are insignificant. The correlations of the 70-hPa QBO index and outflow temperature are significant both before and after 1979,
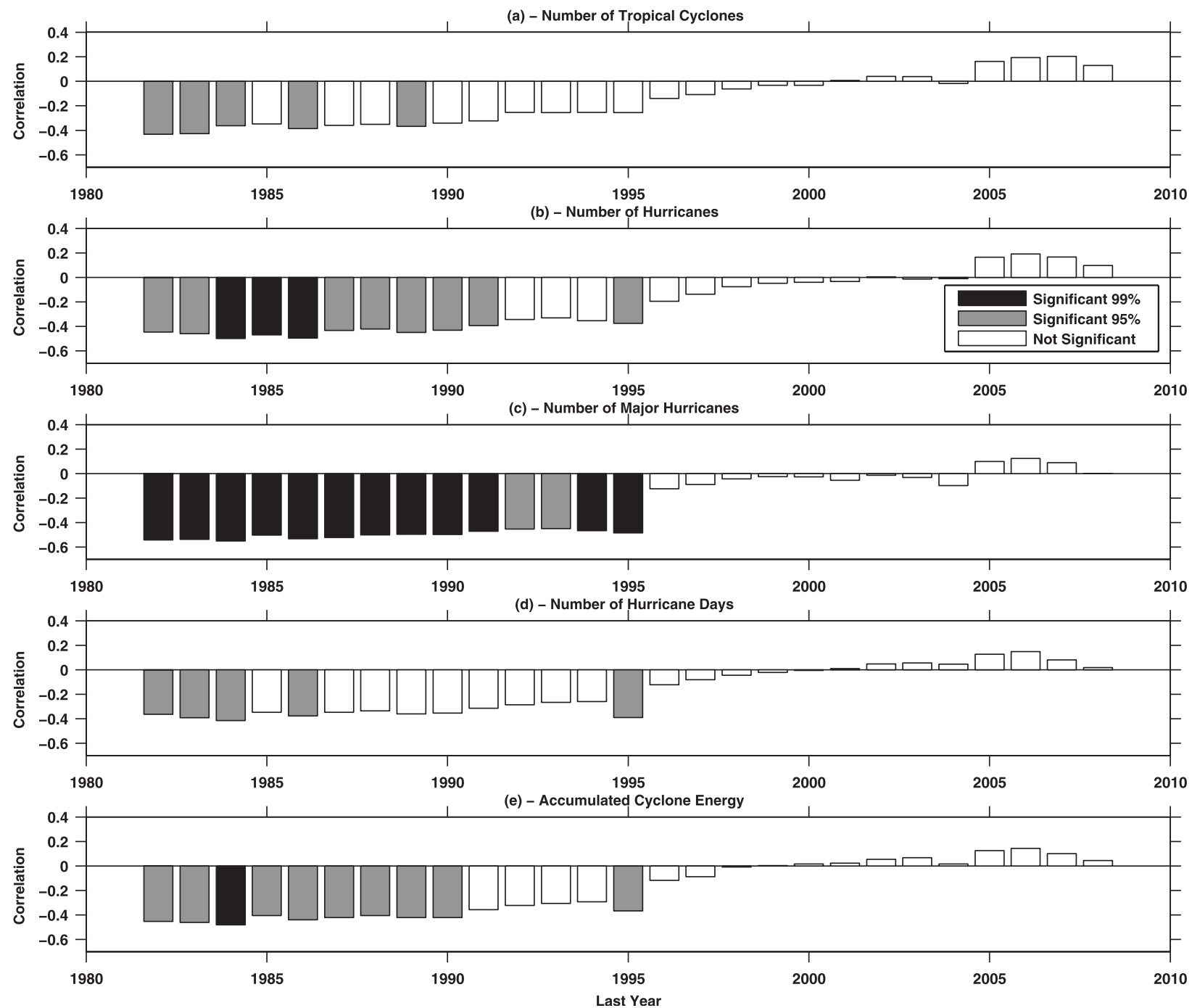

FIG. 8. 30-yr correlations of the solar-QBO index with Atlantic (a) number of tropical cyclones, (b) number of hurricanes, (c) number of major hurricanes, (d) number of hurricane days, and (e) accumulated cyclone energy. The first correlation (first bar) is calculated for the period 1953-82, the subsequent one is calculated for the next 30-yr period (1954-83), until in the last bar the last 30 yr are considered (1979-2008). The $x$ axis shows the last year that was included in the calculation. The statistical significance is calculated by bootstrap. 
TABLE 8. Correlations $(\times 100)$ of Berlin QBO index and various Atlantic TC indices for different time periods. We exclude the years of large volcanic eruptions and two years after these eruptionsthat is, 1963-65, 1982-84, and 1991-93 are excluded. Statistically significant correlations at the $95 \%$ (99\%) level are indicated by an asterisk (double asterisk). The statistical significance was obtained by doing 10000 random permutations of both time series and calculating their correlations. Similar results are obtained with the rank correlation.

\begin{tabular}{lccccc}
\hline \hline \multicolumn{1}{c}{ Period } & NTC & NHUR & NMH & NHD & ACE \\
\hline $1953-2008$ & 06 & 09 & 15 & 20 & 14 \\
$1953-81$ & $44^{*}$ & $45^{*}$ & $67^{* *}$ & $55^{* *}$ & $49 * *$ \\
$1985-2008$ & -17 & -22 & -05 & -14 & -14 \\
\hline
\end{tabular}

and they decrease slightly from the early to late record but again have the wrong sign. Furthermore, the QBOTC correlation remains insignificant for the record as a whole when $70 \mathrm{hPa}$ is used for the QBO index (Table 1).

Investigation of this issue is complicated by the spurious trends in the reanalyses. The QBO signal in tropical tropopause temperature in the NCEP-NCAR reanalysis is known to be unrealistically large in the early record and to have a spurious discontinuity around 1979 (Randel et al. 2000; Huesmann and Hitchman 2003). ERA-40 also has a suspiciously abrupt change in interannual variance of Atlantic 100-hPa temperature around 1979 (not shown; Punge and Giorgetta 2007), although the variance increases rather than decreases at that point, the opposite of NCEP-NCAR. Nonetheless, from the evidence available, it remains difficult to argue that the QBO signal in lower-stratospheric or tropopause temperature can explain the observed QBO-TC relationship.

\section{Other regions}

We reexamine briefly the relationship of QBO with TC activity in regions other than the North Atlantic. As mentioned above, other investigators have discussed the existence of this relationship in other basins, such as the western North Pacific (Chan 1995; Baik and Paek 1998; Lander and Guard 1998; Ho et al. 2009), eastern North Pacific (Whitney and Hobgood 1997), north Indian Ocean (Balachandran and Guhathakurta 1999), and south Indian Ocean (Jury 1993; Jury et al. 1999). In the case of Ho et al. (2009), the influence of the QBO is on the tracks of the western North Pacific TCs. However, ENSO is known to affect tracks of western North Pacific TCs (e.g., Camargo et al. 2007b), and in the analysis of Ho et al. (2009) ENSO effects are not excluded.

Tables 9 and 10 show the correlations of the Berlin QBO and various TC activity indices for the Southern and Northern Hemisphere, respectively. In the Southern Hemisphere, only in the Australian (AUS) Basin are
TABLE 9. Correlations $(\times 100)$ of Berlin QBO and various TC indices for different time periods and Southern Hemisphere basins: SI, AUS, and the South Pacific (SP). The TC indices were calculated for the July-June season and the QBO index used was for the January-March season. Statistically significant correlations at the $95 \%$ level are indicated by an asterisk.

\begin{tabular}{llrrrrr}
\hline \hline Basin & \multicolumn{1}{c}{ Period } & NTC & NHUR & NMH & NHD & ACE \\
\hline SI & $1953-2008$ & 03 & -02 & 10 & -05 & 13 \\
SI & $1953-82$ & 01 & -04 & 14 & -12 & 22 \\
SI & $1983-2008$ & 05 & -04 & 07 & 01 & -02 \\
AUS & $1953-2008$ & -04 & 12 & 06 & 20 & 04 \\
AUS & $1953-82$ & -08 & $33 *$ & 14 & $37 *$ & 05 \\
AUS & $1983-2008$ & 01 & -16 & -06 & -06 & -02 \\
SP & $1953-2008$ & 03 & 03 & 03 & 05 & 08 \\
SP & $1953-82$ & 13 & 10 & 13 & 14 & 09 \\
SP & $1983-2008$ & -11 & -06 & -08 & -06 & 06 \\
\hline
\end{tabular}

the correlations significant. However, similar to the case of the Atlantic, the significance disappears in the second part of the record. This change could possibly be attributed to changes in observational procedures (Buckley et al. 2003; Harper et al. 2008).

In the Northern Hemisphere, other than the North Atlantic, the central North Pacific (CP) basin presents significant correlations for the number of hurricanes and the QBO (in all periods). However, these correlations should be taken with caution because of the small number of TCs in that region. In approximately $26 \%$ of the years, there are no TCs that reach hurricane intensity in the central Pacific. Only in 54\% of the years are there major hurricanes in that basin. The high number of years with zeros leads to higher values of the correlations.

TABLE 10. Correlations $(\times 100)$ of Berlin QBO and various TC indices for different time periods and Northern Hemisphere basins NI, WNP, CP, ENP, and ATL. The TC indices were calculated for the January-December season and the QBO index for the AugustOctober season. Statistically significant correlations at the $95 \%$ (99\%) level are indicated by an asterisk (double asterisk).

\begin{tabular}{llccccc}
\hline Basin & \multicolumn{1}{c}{ Period } & NTC & NHUR & NMH & NHD & ACE \\
\hline NI & $1953-2008$ & 02 & -12 & 07 & -13 & 21 \\
NI & $1953-82$ & 06 & -04 & 15 & -04 & 21 \\
NI & $1983-2008$ & 19 & -16 & 12 & 16 & 46 \\
WNP & $1953-2008$ & -15 & -06 & -07 & 05 & 00 \\
WNP & $1953-82$ & -26 & -10 & -20 & -22 & -16 \\
WNP & $1983-2008$ & -06 & -09 & -02 & 08 & 14 \\
CP & $1953-2008$ & $29 *$ & $27^{*}$ & 20 & 25 & -03 \\
CP & $1953-82$ & 30 & $37^{*}$ & 34 & 32 & -29 \\
CP & $1983-2008$ & 32 & 22 & 20 & 21 & 26 \\
ENP & $1953-2008$ & -06 & 08 & 16 & 11 & -10 \\
ENP & $1953-82$ & -1 & 04 & 21 & 07 & -11 \\
ENP & $1983-2008$ & 13 & 29 & 30 & 28 & -02 \\
ATL & $1953-2008$ & 08 & 11 & 18 & 21 & 17 \\
ATL & $1953-82$ & $44 *$ & $42^{*}$ & $37 *$ & $47 * *$ & $46 *$ \\
ATL & $1983-2008$ & -12 & -13 & -01 & -06 & -06 \\
\hline
\end{tabular}




\section{Conclusions}

Using the longer data record now available, we have reexamined the relationship between tropical cyclone activity and the QBO. Our focus has been on the North Atlantic basin on account of the strong relationship first reported for that basin in the 1980s as well as the relatively high quality of the TC data record there.

The statistically significant relationship between the QBO and North Atlantic TC activity found by Gray (1984a) for the period up to the time of that study is robust to variations in the index of TC activity used and other details of the analysis. However, the relationship is no longer present when the entire record as it currently stands, including data after 1983, is analyzed.

This change in the QBO-TC relationship over the course of the record could be explained in several ways: either the relationship in the early part of the record or the lack of this relationship in the latter part of the record could be a statistical fluke. Alternatively, some additional physical factor could have intervened in such a way as to change the statistical relationship. We have examined several possibilities to explain the change of the relationship between TC activity and the QBO, including ENSO, decadal variability of the QBO, the solar influence on the QBO, and volcanic activity. None of them provide a completely satisfying explanation. The factor which comes closest to doing so, however, is ENSO. ENSO's frequency band strongly overlaps that of the QBO, and the correlation between the two changes sign over the course of the record in the correct direction and at the correct time to explain the change in the QBO-TC relationship. However, excluding the ENSO signal from the analysis (in multiple different ways) does not eliminate the statistically significant correlation in the first part of the record.

We have also briefly explored the QBO-TC relationship in the other basins where TCs occur. In most cases, the correlations are not statistically significant. The only basin that has a statistically significant correlation between the QBO and indices of TC activity in the early record is the Australian basin. That correlation has since disappeared as in the Atlantic, though this change might possibly be attributed to changes in observational procedures.

From these results it is difficult to draw a firm conclusion about whether the QBO exerts a true physical influence on TC activity either in the Atlantic or elsewhere. The lack of a statistically significant relationship in recent decades, the relatively speculative nature of the physical arguments used in the past to explain the relationship, and the change of the ENSO-QBO correlation at around the same time as the QBO-TC correlation becomes insignificant all suggest the conclusion that the QBO does not exert a significant influence on TCs. However, this view requires us to interpret the correlation in the early record as either a pure statistical fluke or a spurious result from the accidental correlation of the QBO with other factors that truly do influence TCs. A pure statistical fluke is unlikely (as indicated by significance tests), and the correlation in the early record remains significant after we attempt to remove other influences - especially, but not only including ENSOthat we might expect to cause a spurious QBO-TC correlation. The difficulty of separating ENSO and the QBO in particular is common to studies on a range of phenomena in the stratosphere as well as troposphere (e.g., Free and Seidel 2009).

Other statistical relationships between different physical phenomena in the climate system have changed on decadal time scales. Prominent among these are the relationship between ENSO and the Indian monsoon (e.g., Krishna Kumar et al. 1999; Torrence and Webster 1999) and between the QBO and the extratropical polar vortices ( $\mathrm{Lu}$ et al. 2008). In both these cases, recognition of the changing relationship has stimulated new research containing new ideas [e.g., see Kucharski et al. (2008) and Ihara et al. (2007) for a small subset of works on the ENSO-monsoon relationship and Anstey and Shepherd (2008) on the QBO-polar vortex relationship]. Given the importance of understanding how large-scale climate variations influence TC activity, we hope that the outstanding puzzle raised by our results here will also stimulate some new insights.

Acknowledgments. We thank Chris Landsea and Phil Klotzbach for discussions that helped to stimulate this paper by pointing out the deterioration of the QBO-TC correlation in recent decades. We thank Kerry Emanuel for discussions on the outflow temperature and the outflow temperature data. We also thank Tony Barnston and Michael Tippett for discussions on statistics and Joanna Haigh for pointing out the references on the combined solar-QBO index. John Knaff's and an anonymous reviewer's comments on an earlier version of this paper contributed to the improvement of this manuscript. The ECMWF ERA-40 data used in this study were obtained from the ECMWF data server. SJC and AHS acknowledge support from NOAA Grant NA08OAR4320912.

\section{REFERENCES}

Anstey, J. A., and T. G. Shepherd, 2008: Response of the northern stratospheric polar vortex to the seasonal alignment of QBO phase transitions. Geophys. Res. Lett., 35, L22810, doi:10.1029/ 2008 GL035721. 
Arpe, K., and S. A. G. Leroy, 2009: Atlantic hurricanes-Testing impacts of local SSTs, ENSO, stratospheric QBO-Implications for global warming. Quat. Int., 195, 4-14.

Baik, J.-J., and J.-S. Paek, 1998: A climatology of sea surface temperature and the maximum intensity of western North Pacific tropical cyclones. J. Meteor. Soc. Japan, 76, 129-137.

Balachandran, S., and P. Guhathakurta, 1999: On the influence of QBO over north Indian Ocean and depression tracks. Meteor. Atmos. Phys., 70, 111-118.

Baldwin, M. P., and T. J. Dunkerton, 2001: Stratospheric harbingers of anomalous weather regimes. Science, 294, 581-584.

— ECMWF ERA-40 reanalysis, rocketsonde data, and rawinsonde data. Geophys. Res. Lett., 32, L09806, doi:10.1029/2004GL022328.

_ - and Coauthors, 2001: The quasi-biennial oscillation. Rev. Geophys., 39, 179-229.

Barnston, A. G., and R. E. Livezey, 1989: A closer look at the effect of the 11-year solar cycle and the quasi-biennial oscillation on the Northern Hemisphere $700 \mathrm{mb}$ height and extratropical North American surface temperature. J. Climate, 2, 12951313.

— $—$, and M. S. Halpert, 1991: Modulation of the Southern Oscillation-Northern Hemisphere midwinter climate relationships by the QBO. J. Climate, 4, 203-217.

_ M. Chelliah, and S. B. Goldenberg, 1997: Documentation of a highly ENSO-related SST region in the equatorial Pacific. Atmos.-Ocean, 35, 367-383.

Bister, M., and K. A. Emanuel, 1998: Dissipative heating and hurricane intensity. Meteor. Atmos. Phys., 65, 233-240.

Black, R. X., B. A. McDaniel, and W. A. Robinson, 2006: Stratosphere-troposphere coupling during spring onset. J. Climate, 19, 4891-4901.

Buckley, B. W., L. M. Leslie, and M. S. Speer, 2003: The impact of observational technology on climate database quality: Tropical cyclones in the Tasman Sea. J. Climate, 16, 2640-2645.

Camargo, S. J., and A. H. Sobel, 2005: Western North Pacific tropical cyclone intensity and ENSO. J. Climate, 18, 2996-3006.

- K. A. Emanuel, and A. H. Sobel, 2007a: Use of a genesis potential index to diagnose ENSO effects on tropical cyclone genesis. J. Climate, 20, 4819-4834.

— A. W. Robertson, S. J. Gaffney, P. Smyth, and M. Ghil, 2007b: Cluster analysis of typhoon tracks. Part II: Large-scale circulation and ENSO. J. Climate, 20, 3654-3676.

— M. C. Wheeler, and A. H. Sobel, 2009: Diagnosis of the MJO modulation of tropical cyclogenesis using an empirical index. J. Atmos. Sci., 66, 3061-3074.

Chan, J. C. L., 1995: Tropical cyclone activity in the western North Pacific in relation to the stratospheric quasi-biennial oscillation. Mon. Wea. Rev., 123, 2567-2571.

Collimore, C. C., D. W. Martin, M. H. Hitchman, A. Huesmann, and D. E. Waliser, 2003: On the relationship between the QBO and tropical deep convection. J. Climate, 16, 25522568.

Elsner, J. B., and A. B. Kara, 1999: Hurricanes of the North Atlantic: Climate and Society. Oxford University Press, $476 \mathrm{pp}$.

—_, and T. H. Jagger, 2008: United States and Caribbean tropical cyclone activity related to the solar cycle. Geophys. Res. Lett., 35, L18705, doi:10.1029/2008GL034431.

$\longrightarrow,-$, and R. E. Hodges, 2010: Daily tropical cyclone intensity response to solar ultraviolet radiation. Geophys. Res. Lett., 37, L09701, doi:10.1029/2010GL043091.

Emanuel, K. A., 1988: The maximum intensity of hurricanes. J. Atmos. Sci., 45, 1143-1155.
_ 1995: Sensitivity of tropical cyclones to surface exchange coefficients and a revised steady-state model incorporating eye dynamics. J. Atmos. Sci., 52, 3969-3976.

Frank, W. M., and G. S. Young, 2007: The interannual variability of tropical cyclones. Mon. Wea. Rev., 135, 3587-3598.

Free, M., and D. J. Seidel, 2009: Observed El Niño-Southern Oscillation temperature signal in the stratosphere. J. Geophys. Res., 114, D23108, doi:10.1029/2009JD012420.

Goldenberg, S. B., C. W. Landsea, A. M. Mestas-Nuñez, and W. M. Gray, 2001: The recent increase in Atlantic hurricane activity: Causes and implications. Science, 293, 474-479.

Gray, W. M., 1984a: Atlantic seasonal hurricane frequency. Part I: El Niño and 30-mb quasi-biennial oscillation influences. Mon. Wea. Rev., 112, 1649-1688.

_ 1984b: Atlantic seasonal hurricane frequency. Part II: Forecasting its variability. Mon. Wea. Rev., 112, 1669-1683.

_ J. D. Sheaffer, and J. Knaff, 1992a: Hypothesized mechanism for stratospheric QBO influence on ENSO variability. Geophys. Res. Lett., 19, 107-110.

$\longrightarrow,-$, and $-1992 \mathrm{~b}$ : Influence of the stratospheric QBO on ENSO variability. J. Meteor. Soc. Japan, 70, 975-995.

Haigh, J. D., and H. K. Roscoe, 2006: Solar influences on polar modes of variability. Meteor. Z., 15, 371-378.

Harper, B. A., S. A. Stroud, M. McCormack, and S. West, 2008: A review of historical tropical cyclone intensity in northwestern Australia and implications for climate change and trend analysis. Aust. Meteor. Mag., 57, 121-141.

Hess, J. C., and J. B. Elsner, 1994: Historical developments leading to current forecast models of Atlantic hurricane activity. Bull. Amer. Meteor. Soc., 75, 1611-1621.

Ho, C.-H., H.-S. Kim, J.-H. Jeong, and S.-W. Son, 2009: Influence of stratospheric quasi-biennial oscillation on tropical cyclone tracks in the western North Pacific. Geophys. Res. Lett., 36, L06702, doi:10.1029/2009GL037163.

Holton, J. R., and H. C. Tan, 1980: The influence of the equatorial quasi-biennial oscillation on the global circulation at $50 \mathrm{mb}$. J. Atmos. Sci., 37, 2200-2208.

— and _ 1982: The quasi-biennial oscillation in the Northern Hemisphere lower stratosphere. J. Meteor. Soc. Japan, 60, 140-148.

Huesmann, A. S., and M. H. Hitchman, 2001: The stratospheric quasi-biennial oscillation in the NCEP reanalyses: Climatological structures. J. Geophys. Res., 106, 11 859-11 874.

— , and — 2003: The 1978 shift in the NCEP reanalysis stratospheric quasi-biennial oscillation. Geophys. Res. Lett., 30, 1048, doi:10.1029/2002GL016323.

Ihara, C., Y. Kushnir, and M. A. Cane, 2007: Indian summer monsoon rainfall and its link with ENSO and Indian Ocean climate indices. Int. J. Climatol., 27, 179-187.

Jury, M. R., 1993: A preliminary study of climatological associations and characteristics of tropical cyclones in the SW Indian Ocean. Meteor. Atmos. Phys., 51, 101-115.

_ - B. Pathack, and B. Parker, 1999: Climatic determinants and statistical prediction of tropical cyclone days in the southwest Indian Ocean. J. Climate, 12, 1738-1746.

Kalnay, E., and Coauthors, 1996: The NCEP/NCAR 40-Year Reanalysis Project. Bull. Amer. Meteor. Soc., 77, 437-441.

Karspeck, A. R., and M. A. Cane, 2002: Tropical Pacific 1976-77 climate shift in a linear, wind-driven model. J. Phys. Oceanogr., 32, 2350-2360.

Klotzbach, P. J., 2007a: Recent developments in statistical prediction of seasonal Atlantic basin tropical cyclone activity. Tellus, 59A, 511-518. 
_ 2007b: Revised prediction of seasonal Atlantic basin tropical cyclone activity from 1 August. Wea. Forecasting, 22, 937-949.

- 2010: On the Madden-Julian oscillation-Atlantic hurricane relationship. J. Climate, 23, 282-293.

— , and W. M. Gray, 2004: Forecasting September Atlantic basin tropical cyclone activity. Wea. Forecasting, 19, 917-934.

$\longrightarrow$, and - 2008: Multidecadal variability in North Atlantic tropical cyclone activity. J. Climate, 21, 3929-3935.

Knaff, J. A., 1993: Evidence of a stratospheric QBO modulation of tropical convection. Colorado State University Tech. Rep., Paper 520, $91 \mathrm{pp}$.

_ 1998 : Predicting summertime Caribbean pressure in early April. Wea. Forecasting, 13, 740-752.

Knapp, K. R., M. C. Kruk, D. H. Levinson, and E. J. Gibney, 2009: Archive compiles new resource for global tropical cyclone research. Eos, Trans. Amer. Geophys. Union, 90, 46, doi:10.1029/ 2009EO060002.

,,--- H. J. Diamond, and C. J. Neumann, 2010: The International Best Track Archive for Climate Stewardship (IBTrACS). Bull. Amer. Meteor. Soc., 91, 363-376.

Kossin, J. P., and D. J. Vimont, 2007: A more general framework for understanding Atlantic hurricane variability and trends. Bull. Amer. Meteor. Soc., 88, 1767-1781.

—_, S. J. Camargo, and M. Sitkowski, 2010: Climate modulation of North Atlantic hurricane tracks. J. Climate, 23, 3057-3076.

Krishna Kumar, K., B. Rajagopalan, and M. A. Cane, 1999: On the weakening relationship between the Indian monsoon and ENSO. Science, 284, 2156-2159.

Kruk, M. C., K. R. Knapp, and D. H. Levinson, 2010: A technique for combining global tropical cyclone best track data. J. Atmos. Oceanic Technol., 27, 680-692.

Kucharski, F., A. Bracco, J. H. Yoo, and F. Molteni, 2008: Atlantic forced component of the Indian monsoon interannual variability. Geophys. Res. Lett., 35, L04706, doi:10.1029/2007GL033037.

Lander, M. A., and C. P. Guard, 1998: A look at global tropical cyclone activity during 1995: Contrasting high Atlantic activity with low activity in other basins. Mon. Wea. Rev., 126, 11631173.

Landsea, C. W., G. D. Bell, W. M. Gray, and S. B. Goldenberg, 1998: The extremely active 1995 Atlantic hurricane season: Environmental conditions and verification of seasonal forecasts. Mon. Wea. Rev., 126, 1174-1193.

Lu, H., M. P. Baldwin, L. J. Gray, and M. J. Jarvis, 2008: Decadalscale changes in the effect of the QBO on the northern stratospheric polar vortex. J. Geophys. Res., 113, D10114, doi:10.1029/2007JD009647.

Maloney, E. D., and D. L. Hartmann, 2000: Modulation of hurricane activity in the Gulf of Mexico by the Madden-Julian Oscillation. Science, 287, 2002-2004.

Mo, K. C., 2000: The association between intraseasonal oscillations and tropical storms in the Atlantic basin. Mon. Wea. Rev., 128, 4097-4107.

Naujokat, B., 1986: An update of the observed quasi-biennial oscillation of the stratospheric winds over the tropics. J. Atmos. Sci., 43, 1873-1877.

Pascoe, C. L., L. J. Crooks, M. N. Juckes, and M. P. Baldwin, 2005: The quasi-biennial oscillation: Analysis using ERA-40 data J. Geophys. Res., 110, D08105, doi:10.1029/2004JD004941.
Plumb, R. A., and R. C. Bell, 1982: A model of the quasi-biennial oscillation on an equatorial beta-plane. Quart. J. Roy. Meteor. Soc., 108, 335-352.

Polvani, L. M., and P. J. Kushner, 2002: Tropospheric response to stratospheric perturbations in a relatively simple general circulation model. Geophys. Res. Lett., 29, 1114, doi:10.1029/ 2001 GL014284.

Punge, H. J., and M. A. Giorgetta, 2007: Differences between the QBO in the first and in the second half of the ERA-40 reanalysis. Atmos. Chem. Phys., 7, 599-608.

Quiroz, R. S., 1983: Relationships among statospheric and tropospheric zonal flows and the Southern Oscillation. Mon. Wea. Rev., 111, 143-154.

Randel, W. J., F. Wu, and D. J. Gaffen, 2000: Interannual variability of the tropical tropopause derived from radiosonde data and NCEP reanalyses. J. Geophys. Res., 105, 15 509-15 523.

, R. R. Garcia, N. Calvo, and D. Marsh, 2009: ENSO influence on zonal mean temperature and ozone in the tropical lower stratosphere. Geophys. Res. Lett., 36, L15822, doi:10.1029/ 2009GL039343.

Ribera, P., D. Gallego, C. Pena-Ortiz, L. Gimeno, R. GarcíaHerrera, E. Hernández, and N. Calvo, 2003: The stratospheric QBO signal in the NCEP reanalysis, 1958-2001. Geophys. Res. Lett., 30, 1691, doi:10.1029/2003GL017131.

Roscoe, H. K., and J. D. Haigh, 2007: Influences of ozone depletion, the solar cycle, and the QBO on the southern annular mode. Quart. J. Roy. Meteor. Soc., 133, 1855-1864.

Shapiro, L. J., 1989: The relationship of the quasi-biennial oscillation to Atlantic tropical storm activity. Mon. Wea. Rev., 117, $1545-1552$.

Torrence, C., and P. J. Webster, 1999: Interdecadal changes in the ENSO-monsoon system. J. Climate, 12, 2679-2690.

Trenberth, K. E., and J. W. Hurrell, 1994: Decadal atmosphereocean variations in the Pacific. Climate Dyn., 9, 303-319.

Uppala, S. M., and Coauthors, 2005: The ERA-40 Re-Analysis. Quart. J. Roy. Meteor. Soc., 131, 2961-3012.

van Loon, H., and K. Labitzke, 1987: The Southern Oscillation. Part V: The anomalies in the lower stratosphere of the Northern Hemisphere in winter and a comparison with the quasibiennial oscillation. Mon. Wea. Rev., 115, 357-369.

Vimont, J. P., and J. P. Kossin, 2007: The Atlantic meridional mode and hurricane activity. Geophys. Res. Lett., 34, L07709, doi:10.1029/2007GL029683.

Wallace, J. M., and F.-C. Chang, 1982: Interannual variability of the wintertime polar vortex in the Northern Hemisphere middle atmosphere. J. Meteor. Soc. Japan, 60, 149-155.

Watanabe, M., and T. Nitta, 1999: Decadal changes in the atmospheric circulation and associated surface climate variations in the Northern Hemisphere winter. J. Climate, 12, 494-510.

Whitney, L. D., and J. Hobgood, 1997: The relationship between sea surface temperature and maximum intensities of tropical cyclones in the eastern North Pacific. J. Climate, 10, 2921-2930.

Zhang, R., 2007: Anticorrelated multidecadal variations between surface and subsurface tropical North Atlantic. Geophys. Res. Lett., 34, L12713, doi:10.1029/2007GL030225.

-, and T. L. Delworth, 2006: Impact of Atlantic multidecadal oscillations on India/Sahel rainfall and Atlantic hurricanes. Geophys. Res. Lett., 33, L17712, doi:10.1029/2006GL026267.

Zhang, Y., J. M. Wallace, and D. S. Battisti, 1997: ENSO-like interdecadal variability: 1900-93. J. Climate, 10, 1004-1020. 